\title{
Detection of Mycobacterium bovis in cattle lungs from two abattoirs in Western and North Central provinces of Sri Lanka
}

\author{
MTLK Jayasumana ${ }^{1}$, DMUNK Dunuwila ${ }^{1}$, PGAS Palkumbura ${ }^{1}$, R Mudalige ${ }^{2}$, IVP Dharmawardana ${ }^{2}$, RRMKK \\ Wijesundera ${ }^{1}$ and HRN Jinadasa ${ }^{1^{*}}$ \\ ' Department of Veterinary Pathobiology, Faculty of Veterinary Medicine and Animal Science, University of Peradeniya, Peradeniya. \\ ${ }^{2}$ Colombo Municipal Council, Colombo 07.
}

\begin{abstract}
Mycobacterium bovis causes bovine tuberculosis (BTB) primarily in cattle. All mammals are susceptible to this zoonotic disease and it had been reported from the Central and North Western provinces of Sri Lanka. Abattoir monitoring is usually used for BTB surveillance in endemic countries. However, proper ante-mortem inspection of cattle and proper meat inspection is practiced only at a few abattoirs in Sri Lanka. The objective of this study was to conduct a preliminary assessment of BTB incidence among cattle used for beef production at two abattoirs in Western (WP) and North Central (NCP) provinces in Sri Lanka. Randomly collected 115 lung samples ( $\mathrm{WP}=45 ; \mathrm{NCP}=70$ ) were tested using direct acid-fast staining, culture on Lowenstein Jensen medium, histopathology and PCR. Mycobacterium tuberculosis complex was detected in $7.0 \%$ of the samples by PCR conducted using DNA extracted directly from samples. Only $5.2 \%$ of the samples (4.45\% from WP and $5.7 \%$ from NCP) were positive for $M$. bovis specific PCR. Only one $(0.87 \%)$ PCR positive sample from NCP had a granuloma on histopathological observation, suggesting relatively low incidence of BTB among the cattle processed at these abattoirs. Mycobacterium bovis isolates were not recovered and acid-fast bacilli were not observed in direct smears. Initiating proper meat inspection at all abattoirs in the country along with increased BTB surveillance capacity of the national veterinary service are required to mitigate this risk. Further studies are essential to determine the exact prevalence of BTB in Sri Lanka and to identify any wildlife reservoirs of $\mathrm{BTB}$ in the country.
\end{abstract}

Keywords: Abattoirs, bovine tuberculosis, cattle, Mycobacterium bovis.

\section{INTRODUCTION}

Bovine tuberculosis (BTB) is a notifiable livestock disease caused by Mycobacterium bovis (OIE, 2008). Cattle are the primary host for $M$. bovis, but all mammals are susceptible to the disease. Therefore, it is an important zoonotic disease and a potential occupational hazard in the livestock industry (Quinn et al., 2015). However, personto-person transmission is rare among immunocompetent individuals (Sunder et al., 2009; WHO, 2017). The prevalence of BTB is higher in developing countries compared to most developed countries due to inefficient control programmes in developing countries (De la RuaDomenech et al., 2006; Une \& Mori, 2007). National BTB control programmes have been established in many countries with special emphasis on cattle industry (Westrell et al., 2009; Max et al., 2011; Allen et al., 2018). These control programmes generally consist of prevention, surveillance and eradication strategies. The prevention of BTB addresses the herd hygiene and specific biosecurity practices minimizing the pathogen exposure. Routine surveillance methods for $M$. bovis include antemortem inspection of cattle mainly including tuberculin skin test and meat inspection at abattoirs (Schiller et al., 2010). Whole-herd depopulation could be used to eradicate M. bovis from domestic skin test positive herds and restocking is allowed after a waiting period as the organism may persist in soil for up to 12 months

*Corresponding author (rnjinadasa@vet.pdn.ac.lk; iD https://orcid.org/0000-0001-8538-782X) 
depending on the environmental conditions (OIE, 2008; Fine et al., 2011; Good \& Duignan, 2011; Barbier et al., 2016). However, the 'test and slaughter' policy is widely practiced as an alternative strategy for whole-herd depopulation owing to the financial and animal welfare constraints. Test and slaughter is the accepted method of BTB eradication by the World Organization for Animal Health (Office International des Epizooties-OIE) at present (OIE, 2008; Good \& Duignan, 2011).

Abattoir monitoring for BTB is a key surveillance technique in endemic countries and considered as the base for granting and maintaining official BTB-free status for a country (Collins, 2006; De la Rua-Domenech et al., 2006; Radunz, 2006; OIE, 2008). Having an effective routine meat inspection service as a part of BTB surveillance programme also safeguards the public health since BTB is one of the foodborne zoonoses. According to the standard procedures, all cattle entering the food chain should be subjected to ante-mortem examination and proper post-mortem meat inspection should be conducted on dressed carcasses (Amanfu, 2006). In reference to BTB, the carcass is recommended as fit for human consumption when the animal is clinically healthy in ante-mortem inspection and shows no tuberculosis lesions in post-mortem examination (Annon, 1893). However, most developing countries with endemic tuberculosis may not practice fully effective meat inspection protocols due to the limitations in financial allocations, trained personnel and efficient data recording systems in order to trace back the infected animal sources (Ayele et al., 2004; Michel et al., 2010). Ideally all meat inspections need to be conducted under the supervision of a licensed veterinarian specifically trained for the purpose (Haddad et al., 2004). Even though the carcasses from healthy cattle without visible tuberculous lesions can be certified as fit for human consumption, M. bovis DNA can be detected in infected animal tissue well before the appearance of gross lesions (Swift et al., 2016). Therefore, inclusion of molecular detection methods may increase the sensitivity of abattoir monitoring for BTB (Proano-Perez et al., 2011; Sa'idu et al., 2015b; Silva et al., 2018b).

According to the beef production statistics in Sri Lanka, around 150,000 cattle are being processed annually at licensed abattoirs island-wide (Department of Census and Statistics, 2019). The total beef production in Sri Lanka is approximately 30 MT/year (DAPH, 2016). Most of the cattle (approximately $45 \%$ ) are processed in abattoirs in the Eastern province followed by Northern and North Western provinces (approximately $15 \%$ each) according to the average production volumes of last five years, (Department of Census and Statistics, 2019). The procedure for inspecting meat produced for human consumption is regulated by the butcher's ordinance in Sri Lanka (Annon, 1893). According to the provisions in the Butcher's Ordinance, the legal power for meat inspection is vested with respective local authorities (Annon, 1893). However, many local authorities in Sri Lanka do not have sufficient resources to retain the services of a specially trained veterinarian or any other specifically trained staff for proper meat inspection on a regular basis. These lapses in food safety particularly in major municipalities are attributable not only to the financial limitations, but also to the sensitive religious and cultural reservations on beef production in Sri Lanka (Alahakoon et al., 2016). Although the sale of beef is not legally banned in any locality in Sri Lanka, many major municipalities have withdrawn the support to operate abattoirs due to these religious and cultural issues. The few existing municipal abattoirs do not process live cattle, and only receive dressed carcasses from wholesale fresh meat dealers for inspection and distribution. This prevailing practice regrettably allows beef produced at unauthorized establishments to enter the local market (Alahakoon et al., 2016).

Bovine tuberculosis had been suspected in Sri Lanka for several years and confirmed since 2012 (Kumara et al., 2014; DAPH, 2016; Kumara, 2017). Several cases have been reported from the Central province and relatively high herd prevalence of positive reactors were detected in twenty herds from the same province (Kumara, 2017). One tuberculosis positive carcass was detected at post-mortem examination in Kandy municipal abattoir and the affected animal had originated from the North Western province (Kumara et al., 2015). No data is currently available on the prevalence of BTB in any province other than the Central and North Western provinces in Sri Lanka. Therefore, the objective of this study was to undertake a preliminary assessment of the incidence of BTB in lungs of cattle carcasses at two abattoirs located in the Western province (WP) and North Central province (NCP) in Sri Lanka using direct acidfast staining, microbiological culture, histopathology and PCR.

\section{METHODOLOGY}

\section{Selection of abattoirs}

Two abattoirs located in the WP (Colombo district) and NCP (Anuradhapura district) were selected for sampling. Approximately $15 \%$ of total beef produced in Sri Lanka are processed at abattoirs located in WP and NCP. Each 
province has an approximately equal processing capacity (Department of Census and Statistics, 2019). Selection of abattoirs was based on convenience and daily processing capacity. Further, previous BTB surveillance data are not available for WP and NCP. The abattoir in WP receives carcasses of cattle originating from the entire country and live cattle are no longer processed at this abattoir. The abattoir in NCP receives live cattle for processing mainly from NCP. Ante-mortem veterinary inspection of cattle is not practiced at both of these abattoirs, but routine meat inspection by a trained veterinarian is practiced at the abattoir in WP.

\section{Sample collection}

An expected prevalence of $8 \%$ was assumed for the calculation of sample size based on previous studies on BTB incidence in abattoirs in other endemic countries (Echeverría et al., 2014; Srinivasan et al., 2018). Thrusfield formula at $95 \%$ confidence interval and $5 \%$ desired absolute precision was used (Thrusfield, 2005).

$$
n=Z^{2} \times P_{e x p}\left(1-P_{e x p}\right) / d^{2}
$$

[ $n=$ required sample size, $Z=$ confidence interval (CI at $95 \%), P_{\text {exp }}=$ expected prevalence of BTB in test unit, $d=$ desired absolute precision $(5 \%)]$

Accordingly, 115 lung samples were collected from the abattoirs (WP; $n=45$ and NCP; $n=70$ ) over a period of 2 months (from September to November 2019). The samples were collected immediately after the dressed carcasses were brought to the abattoir (WP) or immediately after slaughter (NCP). Samples from cranial lung lobes were separately collected into sterile containers, stored in ice and transported on the same day to the laboratory. Approximately the same anatomic location was sampled from all lungs. Each lung sample was divided into three sections and impression smears were prepared for Ziehl-Neelsen (ZN) staining. The sections for culture were processed immediately. The sections for DNA extraction were frozen at $-20{ }^{\circ} \mathrm{C}$ while the sections for histopathology were fixed in $10 \%$ neutral buffered formalin at 1:10 (sample/ formalin) ratio and stored at room temperature until further processing.

\section{Ziehl-Neelsen (ZN) staining}

Direct impression smears from lung samples were used immediately for $\mathrm{ZN}$ staining. The slides were stained manually according to the standard protocols (Varello et al., 2008). All slides were examined by scanning the entire area at $1000 \mathrm{x}$ magnification. Samples were considered positive when at least one acid-fast bacillus was detected in at least one high-power field (Varello et al., 2008). Smears were also prepared from bacterial isolates and were also stained manually according to the standard protocols (Varello et al., 2008).

\section{Culture procedure for $M$. bovis and $M$. tuberculosis complex (MTBC)}

Samples were cultured on standard Lowenstein Jensen (LJ) medium with standard $\mathrm{NaOH}$ decontamination (Kent, 1985; Tripathi et al., 2014). Briefly, $1 \mathrm{~g}$ of sample was decontaminated by adding an equal volume of $4 \%$ $\mathrm{NaOH}$ and leaving at room temperature for $10 \mathrm{~min}$. Then it was centrifuged at $3000 \mathrm{~g}$ for $5 \mathrm{~min}$ and supernatant was discarded. The sediment was re-suspended in distilled water at 1:1 ratio. Thereafter, it was centrifuged at $3000 \mathrm{~g}$ for $5 \mathrm{~min}$ and supernatant was discarded. Afterwards, $500 \mu \mathrm{L}$ of normal saline was added to the sediment and left for another 5 min and supernatant was poured off (Kent, 1985; Tripathi et al., 2014). Finally, the decontaminated lung samples were cultured in duplicate on LJ medium (Oxoid, UK) slants prepared with and without sodium pyruvate and incubated with closed caps at $37^{\circ} \mathrm{C}$. Culture bottles were observed for growth daily for first week and thereafter at weekly intervals for $8 \mathrm{wk}$. Slants with sodium pyruvate enhances the growth of $M$. bovis while the slants without sodium pyruvate supports the growth of other pathogenic members of MTBC (Wagari, 2016).

\section{Histopathology}

Formalin-fixed samples were processed and waxembedded according to the standard protocols. Then the wax-embedded tissues were sectioned at $2 \mu \mathrm{m}$ thickness and stained with hematoxylin and eosin (Souza et al., 2013). The slides were examined under light microscope at $1000 \mathrm{x}$ magnification.

\section{DNA extraction and PCR}

The DNA was extracted from lung tissue samples and all acid-fast bacilli (AFB) isolates using Reliaprep ${ }^{\mathrm{TM}}$ gDNA Tissue Miniprep kit (Promega, USA) after proteinase K digestion according to the manufacturer's instructions. The PCR amplification of extracted DNA was performed with mycobacterial regions of difference 4 and 9 (RD4 and RD9) flanking primers while positive samples were confirmed with RD4 and RD9 internal primers according to published validated protocols (Brosch et al., 2002; Yahyaoui-Azami et al., 2017; Jayasumana et al., 2018a). The combined RD4 and RD9 flanking and internal PCR 
assay allows the simultaneous diagnosis of $M$. bovis and other pathogenic members of MTBC (Brosch et al., 2002; Yahyaoui-Azami et al., 2017).

Primer sequences;

RD4 Flanking F - CTCGTCGAAGGCCACTAAAG RD4 Flanking R - AAGGCGAACAGATTCAGCAT RD4 Internal F - CAAGGGGTATGAGGTTCACG RD4 Internal R - CGGTGATTCGTGATTGAACA RD9 Flanking F - GTGTAGGTCAGCCCCATCC RD9 Flanking R - GCCCAACAGCTCGACATC RD9 Internal F - CGATGGTCAACACCACTACG RD9 Internal R - CTGGACCTCGATGACCACTC

The reaction mixture for all PCR assays contained $10 \mu \mathrm{L}$ of $2 \mathrm{x}$ PCR master mix (Promega, USA), $0.5 \mu \mathrm{L}$ of each forward and reverse primers $(10 \mathrm{pmol} /$ $\mu \mathrm{L}), 7 \mu \mathrm{L}$ of nuclease free water and $2 \mu \mathrm{L}$ of DNA template in a volume of $20 \mu \mathrm{L}$. All PCR reactions were performed in a Veriti ${ }^{\circledR}$ thermal cycler (Thermo Fisher Scientific, USA). The cycling conditions for all PCR reactions were an initial denaturation at $95{ }^{\circ} \mathrm{C}$ for 15 min followed by 30 cycles of denaturation at $94{ }^{\circ} \mathrm{C}$ for $1 \mathrm{~min}$, annealing at $61{ }^{\circ} \mathrm{C}$ for $1 \mathrm{~min}$ and primer extension at $72{ }^{\circ} \mathrm{C}$ for $1 \mathrm{~min}$ with a final extension at $72{ }^{\circ} \mathrm{C}$ for 10 min (Brosch et al., 2002; Warren et al., 2006; Yahyaoui-Azami et al., 2017; Jayasumana et al., 2018a). The amplified products were analysed by electrophoresis on a $1.5 \%$ agarose gel stained with ethidium bromide.

\section{RESULTS AND DISCUSSION}

This preliminary assessment was undertaken to investigate the incidence of BTB among cattle processed at two abattoirs located in the Western and North Central provinces of Sri Lanka. Randomly collected samples from cranial lung lobes were used in this study. Different organs including lungs, lymph nodes, intestines, liver, spleen and heart have been used in previous abattoir surveys for BTB (Müller et al., 2008; Cardoso et al., 2009; Proano-Perez et al., 2011; Gizaw et al., 2017; Yahyaoui-Azami et al., 2017; Silva et al., 2018b). Among these organs, the highest number of BTB positive cases were associated with lung and lymph node lesions (Sa'idu et al., 2015b; Silva et al., 2018b). The presence of lung lesions had the strongest association with the detection of $M$. bovis infection by PCR (Sa'idu et al., 2015b; Silva et al., 2018b). Cranial lung lobes are commonly associated with pulmonary lesions of BTB (Menin et al., 2013). Live cattle are no longer processed at the abattoir in WP. Therefore, suspected BTB lesions may be removed prior to the presentation of dressed carcasses for meat inspection at this abattoir. Additionally, proper meat inspection under veterinary supervision is not available at the abattoir in NCP. Therefore, random sampling from cranial lung lobes was used at both abattoirs to avoid any bias. However, no suspected tuberculosis lesions were reported at meat inspection from the abattoir in WP during the study period.

Direct acid-fast staining, microbiological culture, histopathology and PCR were used for this investigation. Acid-fast bacilli were not observed in any of the impression smears prepared directly from the lung tissue samples during the current survey. Mycobacterium bovis or MTBC cultures were also not recovered from any of the samples after 8 weeks of incubation. The $M$. bovis isolation rates and $\mathrm{AFB}$ detection rates in direct impression smears from cattle lungs without gross BTB lesions are generally very low (Proaño-Pérez et al., 2011; Quinn et al., 2015). However, three rapid growing AFB isolates $(2.6 \%, 3 / 115)$ were recovered within one week of culture (Figure 1A). All three AFB cultures were confirmed as non-tuberculosis mycobacteria (NTM) on the basis of rapid growth and absence of positive bands with RD9 flanking PCR (Brosch et al., 2002; Warren et al., 2006). Isolation rates of NTM in abattoir surveys for BTB in previous studies were 2-3\% (Araújo et al., 2005). Therefore, the NTM isolation rate observed in the current study was comparable with previous studies. The NTM cultures were not characterised further. Additionally, two samples had fungal contaminants. The observed fungal contamination rate $[1.7 \%(2 / 115)]$ was relatively low. Fungal contamination rates up to $8 \%$ have been observed during abattoir surveys for BTB in previous studies using the same $\mathrm{NaOH}$ decontamination and $\mathrm{LJ}$ medium culture method (Chatterjee et al., 2013).

M. tuberculosis complex was detected in $7 \%$ of the samples (8/115) during the initial screening PCR assays using RD9 flanking primers (Figure 1C). Among the eight samples that were PCR positive for MTBC, M. bovis was detected in six $(5.2 \%, 6 / 115)$ samples (Figure 2). Out of the six M. bovis positive samples, two originated from the abattoir in WP, while the remaining four samples originated from the abattoir in NCP, representing approximately equal incidence (4.45\% in WP and $5.7 \%$ in NCP) of $M$. bovis infection in the two abattoirs surveyed in the current study (Figure 1D). All PCR results were confirmed by performing at least two independent assays. The detection rate of MTBC other than M. bovis by PCR in the current study was relatively very low $[1.7 \%(2 / 115)]$ compared to similar previous studies. The detection rates of MTBC other than M. bovis by PCR were $10-13 \%$ in previous abattoir surveys of BTB (Araújo et al., 2005; Silva et al., 2018b). 


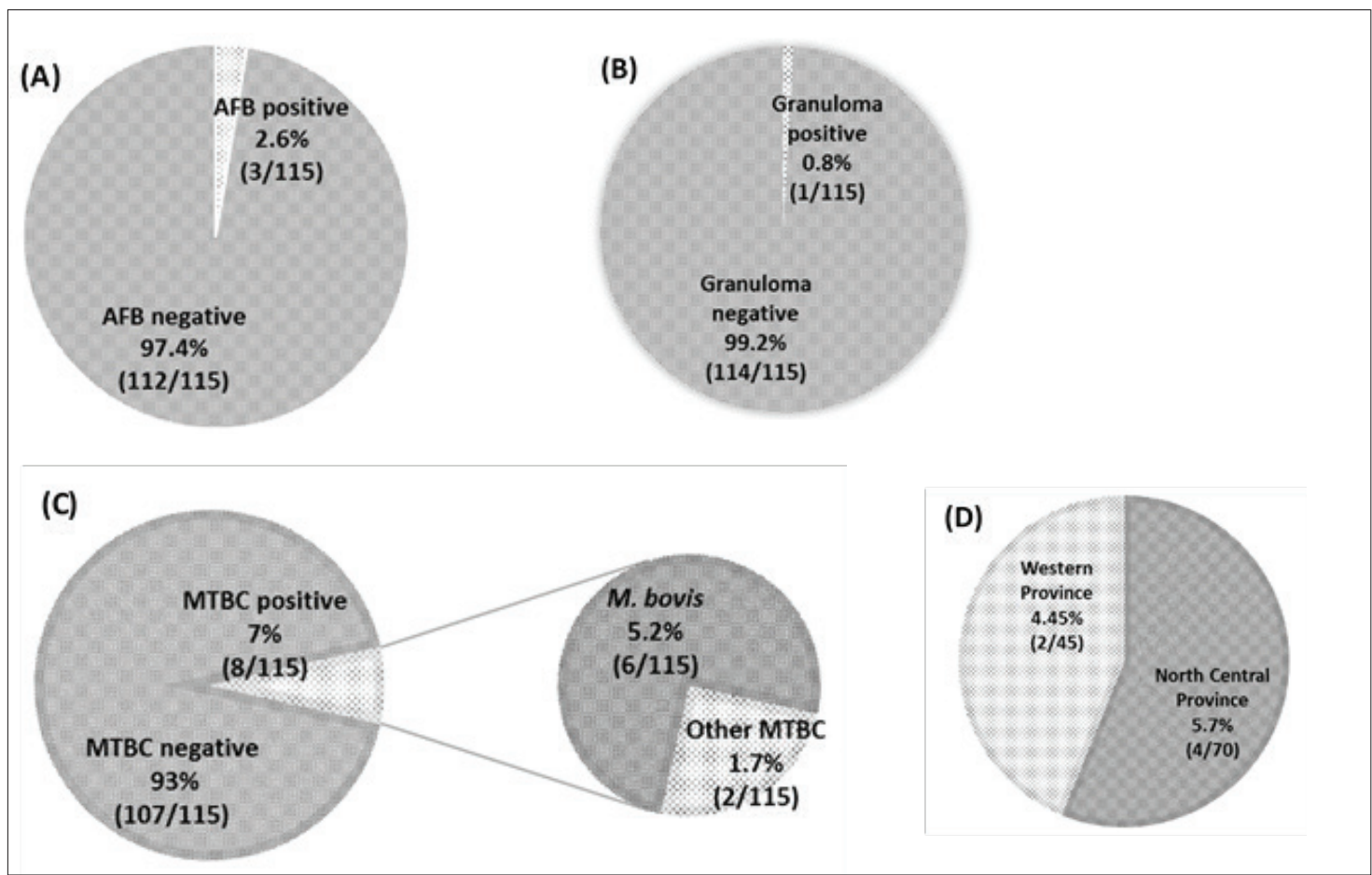

Figure 1: Isolation rates of acid-fast bacilli (AFB) from lung samples cultured on Lowenstein Jensen medium (A); detection rate of granuloma in lung samples in histopathology (B); detection rates of M. tuberculosis complex (MTBC) and M. bovis by PCR using DNA extracted directly from lung tissue (C); the distribution of $M$. bovis PCRpositive samples between North Central and Western Provinces (D).

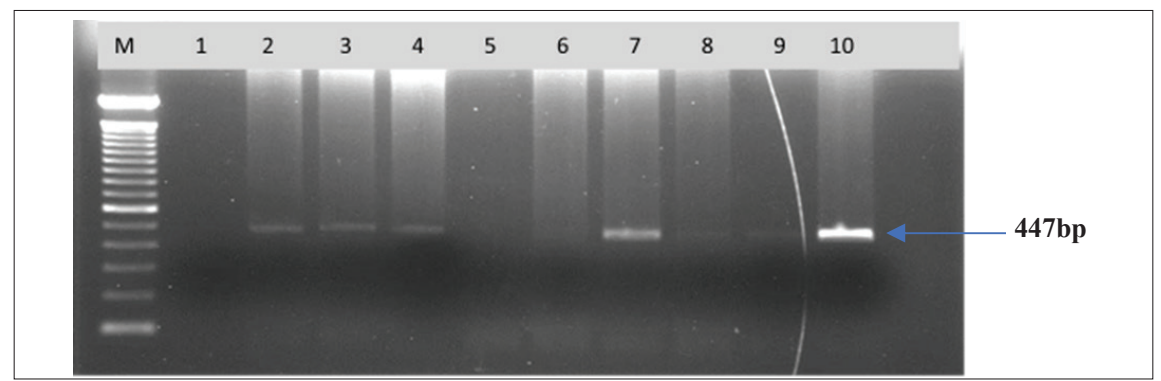

Figure 2: Representative ethidium bromide-stained agarose gel of RD4 flanking PCR. Lane M: 100 bp DNA ladder; lane1: negative control; lanes 2, 3, 4, 7, 8, 9: M. bovis positive amplified DNA from lung samples; lanes 5, 6: M. bovis negative amplified DNA from lung samples; lane 10: $M$. bovis positive control DNA. Expected 447 bp product confirms the presence of M. bovis.

A granuloma was observed in histopathological examination in one of the PCR-positive samples, which was obtained from the NCP (Figures 1B, Figures 3A, 3B). Concentric layers of fibroblasts with lymphocytic and macrophage aggregations were observed in the granuloma in addition to compression of the adjacent lung parenchyma (Figure 3A). Furthermore, an area of caseous necrosis with mild calcification was observed in the centre of the granuloma (Figure 3B). Another PCR positive sample originating from NCP showed 
atypical pneumonia with destruction of alveoli, moderate consolidation and aggregation of leukocytes (Figure 3C, 3D). Rest of the PCR-positive samples and all of the PCR-negative lung samples showed mild emphysema and varying degree of congestion (Figure 3E, 3F).
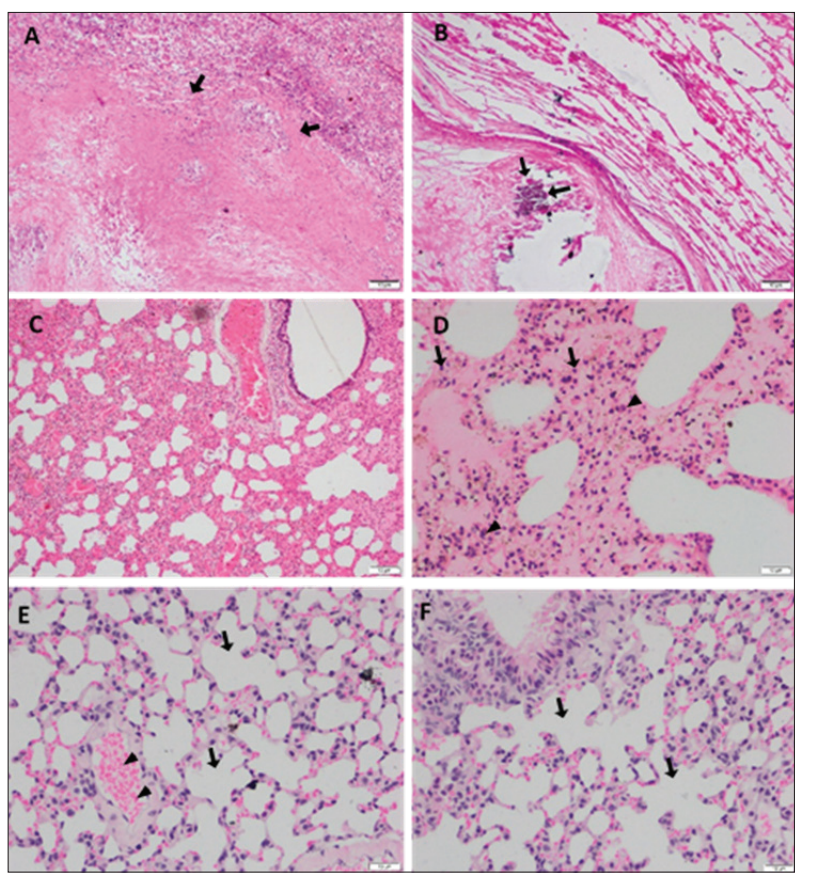

Figure 3: Representative photomicrographs of hematoxylin and eosin-stained lung sections that were PCR-positive (A-D) and PCR-negative for M. bovis (E and F). A granuloma (arrows) compressing adjacent lung parenchyma is observed (A). Caseous necrosis (arrows) with mild calcification is observed in the centre of the granuloma (B). Atypical pneumonia with destruction of alveoli is observed (C). Aggregations of lymphocytes (arrows) and macrophages (arrow heads) are observed in the lungs with atypical pneumonia (D). Mild emphysema (arrows) and congestion (arrow heads) is observed in PCR-negative lung tissues $(\mathrm{E}$ and $\mathrm{F}) . \mathrm{Bar}=100 \mathrm{~mm}$

The incidence of $M$. bovis infection observed among cattle processed at the two abattoirs in WP and NCP in Sri Lanka during the current study was relatively low (5.2\%). Similar previous studies conducted in several endemic countries have frequently reported $>10 \%$ BTB incidence (Proano-Perez et al., 2011; Sa'idu et al., 2015b; Silva et al., 2018b). However, abattoirs in Sri Lanka including these two abattoirs do not maintain complete cattle movement history records. Therefore, the observed incidence of $M$. bovis infection does not necessarily indicate the disease burden in WP or NCP. Bovine tuberculosis has been previously detected and confirmed in a cattle carcass processed at the Kandy municipal abattoir. The affected animal had originated from the North Western province (Kumara et al., 2015). Based on the Mycobacterial Interspersed Repetitive Unit - Variable Number Tandem Repeat (MIRU-VNTR) typing, this $M$. bovis strain was genetically distinct from several other M. bovis strains from BTB cases in Central Province (Jayasumana et al., 2018b).

Good agreement between bacteriological culture, AFB in impression smears and PCR results were not observed in the current study. This may be partly attributable to contamination of lung samples as carcasses are not handled separately at the abattoirs. Comparatively similar results were observed in an abattoir survey of BTB conducted among apparently healthy cattle in Palestinian Territories (Ereqat et al., 2013). A total of $2.9 \%(6 / 208)$ lung samples without gross BTB lesions were positive for $M$. bovis specific PCR while only one sample was positive for AFB (Ereqat et al., 2013). No bacterial growths were observed from the cultured lung, liver and kidney tissues after 8 weeks of incubation using the same $\mathrm{NaOH}$ decontamination and LJ medium similar to the ones used in the present study (Ereqat et al., 2013). Similarly, in another study that sampled cattle with gross BTB lesions, only $56 \%(28 / 50)$ of lymph node samples having caseous tuberculous lesions had positive cultures while granuloma formation was observed in $64 \%$ of the samples (Silva et al., 2018a). Only $12 \%$ of the samples was positive for AFB. Mycobacterium bovis was detected by PCR only in $20 \%$ of the samples (Silva et al., 2018a). Contrary to these results, several other studies that sampled cattle with gross BTB lesions have reported good agreement between culture and PCR (Cardoso et al., 2009; Proano-Perez et al., 2011; Gizaw et al., 2017; Yahyaoui-Azami et al., 2017; Silva et al., 2018b). Meat inspection protocols may vary in different jurisdictions. Therefore, the sensitivity of detecting gross lesions of BTB at post-mortem examination may vary according to the protocol employed for meat inspection, anatomical sites examined and the stage of infection since early stage of the disease may result in lower detection rates (Corner, 1994).

Although culture is considered the gold standard test for diagnosing $M$. bovis, identification rates are low compared to molecular diagnostic methods (Ayele et al., 2004). This could be due to several factors including the presence of very low number of live bacteria in tissues, subclinical infection or early stage of disease 
and destruction of live bacteria during sample transport and decontamination process or freeze-thawing cycles (Palomino \& Portaels, 1998; Proaño-Pérez et al., 2011). Routine $\mathrm{NaOH}$ decontamination protocol and culturing on LJ medium slants were used in the current study due to budgetary limitations. Samples were not frozen before culture. Nearly $100 \%$ isolation rates were previously achieved under the same culture conditions from local cattle lung samples with visible BTB lesions (Kumara et al., 2014; Kumara et al., 2015). Stonebrink-Leslie medium have been shown to have better $M$. bovis isolation rates than LJ medium (Proaño-Pérez et al., 2011; Silva et al., 2018a). Up to $50 \%$ isolation rates were observed on Stonebrink-Leslie medium while no bacterial growths were observed on LJ medium (ProañoPérez et al., 2011; Silva et al., 2018a).

Approximately $60 \%$ of all human pathogens and nearly $75 \%$ of all recently emerging diseases in humans are zoonotic (FAO, 2019). Although M. tuberculosis is the main causative agent for human tuberculosis, approximately $3 \%$ of human tuberculosis cases are due to M. bovis infections (Cosivi et al., 1998). Therefore, BTB has been listed as one of the seven neglected zoonotic diseases in the world by the WHO (Ayele et al., 2004). It is also listed as one of the important zoonotic diseases in Latin America, Africa and Asia (De la Rua-Domenech, 2006; Smith et al., 2006). Zoonotic M. bovis- induced tuberculosis in humans have not been reported in Sri Lanka (Müller et al., 2013; NPTCCD, 2016). This may be due to underreporting as all AFB positive patients are reported as having 'bacteriologically confirmed TB' in Sri Lanka without any further investigations (NPTCCD, 2016). However, two confirmed cases of tuberculosis in Sri Lankan elephants were caused by M. tuberculosis strains that are similar to East-African-Indian (EAI) lineage commonly circulating among humans in the country according to MIRU-VNTR typing (Perera et al., 2014; Jayasumana et al., 2018b).

Infected cattle and carcasses may pose a risk to the workers in abattoirs, by exposing them to M. bovis while handling infected animals or products from infected animals (Tibebu et al., 2014). Handling and consumption of uncooked or partially cooked meat from infected cattle may be a source of infection of $M$. bovis to consumers (LoBue et al., 2003; Thoen et al., 2006; Sa'idu et al., 2015a). However, consumption of unpasteurised milk or dairy products is considered as the primary risk factor for M. bovis infection in humans (Leite et al., 2003; De la Rua-Domenech, 2006; Kinde et al., 2007). According to the limited information available, $M$. bovis has not been detected in raw milk in Sri Lanka and all milk products currently available in Sri Lanka are either pasteurised or sterilised (Jayasumana et al., 2018a). Therefore, the zoonotic risk of $M$. bovis remains low in Sri Lanka.

The cattle processed at the abattoir in NCP were largely originated from the herds managed under extensive cattle management system in the dry zone of Sri Lanka. These cattle herds roam freely and always interact with wild animals at the boarders of the forests and even within the national parks. Therefore, existence of $M$. bovis positive animals in these herds pose a potential risk for introducing $M$. bovis to wildlife or may be an indication of carrying the infection from a wildlife reservoir to domestic cattle herds. Since occurrence of $M$. bovis in wildlife is not yet reported in Sri Lanka, the source of infection of these infected cattle is unknown. Control programmes in Europe and North America have shown that M. bovis can be controlled as long as it is restricted to livestock (Fitzgerald \& Kaneene, 2013; Miller \& Sweeney, 2013). Eradication is nearly impossible once it has spread into wildlife (Cantas \& Suer, 2014). Classic examples of well-established stable wildlife reservoirs of M. bovis are European badger in the United Kingdom (Cheeseman et al., 1989), elk in Canada (Wobeser, 2009) and white-tailed deer in the USA (O'Brien et al., 2006).

Detection of M. bovis even at a low incidence from two abattoirs under less than optimal laboratory conditions suggest that apparently healthy cattle may be a potential source of M. bovis infection in Sri Lanka that may pose a risk to public health. Therefore, appropriate measures including regularised meat inspection at all abattoirs are required together with increased BTB surveillance capacity of the national veterinary service to mitigate this risk. Further studies are essential to determine the exact prevalence of BTB in Sri Lanka and to identify any wildlife reservoirs of BTB in the country.

\section{CONCLUSIONS}

Relatively low incidence of $M$. bovis infection (5.2\%) was observed among apparently healthy cattle processed at two abattoirs in the Western and North Central provinces in Sri Lanka. Only one PCR positive sample had a granuloma. Detecting M. bovis among extensively managed cattle herds in the dry zone is a potential challenge for controlling BTB in the country. Therefore, increased BTB surveillance and strengthening the testing capacity of the national veterinary service is essential to mitigate this risk. 


\section{Acknowledgements}

This study was funded by National Research Council Sri Lanka grant number 15-110. Authors thank Dr Noel Smith from the Animal and Plant Health Agency, United Kingdom for providing $M$. bovis specific DNA to be used for positive control. Authors also thank Mrs. W. Jayaweera from the Department of Veterinary Pathobiology, University of Peradeniya for technical assistance.

\section{REFERENCES}

Alahakoon A.U., Jo C. \& Jayasena D.D. (2016). An overview of meat industry in Sri Lanka: A comprehensive review. Korean Journal for Food Science of Animal Resources 36(2): 137-144. DOI: https://doi.org/10.5851/kosfa.2016.36.2.137

Allen A.R., Skuce R.A. \& Byrne A.W. (2018). Bovine tuberculosis in Britain and Ireland-A perfect storm? the confluence of potential ecological and epidemiological impediments to controlling a chronic infectious disease. Frontiers in Veterinary Science 51: 1-17.

DOI: https://doi.org/10.3389/fvets.2019.00213

Amanfu W. (2006). The situation of tuberculosis and tuberculosis control in animals of economic interest. Tuberculosis 86(3-4): 330-335.

DOI: https://doi.org/10.1016/j.tube.2006.01.007

Annon (1893). Ordinance No. 09 of 1893 as amended "Butchers Ordinance". Available at http://extwprlegs1.fao.org/docs/ $p d f / s r l 37153 . p d f$. Accessed on 5 January 2020.

Araújo C.P.D., Leite C.Q.F., Prince K.A.D., Jorge K.D.S.G. \& Osório A.L.A.R. (2005). Mycobacterium bovis identification by a molecular method from post-mortem inspected cattle obtained in abattoirs of Mato Grosso do Sul, Brazil. Memórias do Instituto Oswaldo Cruz 100(7): 749-752.

DOI: https://doi.org/10.1590/s0074-02762005000700013

Ayele W.Y., Neill S.D., Zinsstag J., Weiss M. \& Pavlik I. (2004). Bovine tuberculosis: an old disease but a new threat to Africa. The International Journal of Tuberculosis and Lung Disease 8(8): 924-937.

Barbier E., Boschiroli M.L., Gueneau E., Rochelet M., Payne A., De Cruz K., Blieux A.L., Fossot C. \& Hartmann A. (2016). First molecular detection of Mycobacterium bovis in environmental samples from a French region with endemic bovine tuberculosis. Journal of Applied Microbiology 120(5): 1193-1207

DOI: https://doi.org/10.1111/jam.13090

Brosch R., Gordon S.V., Marmiesse M., Brodin P., Buchrieser C., Eiglmeier K., Garnier T., Gutierrez C., Hewinson G. \& Kremer K. (2002). A new evolutionary scenario for the Mycobacterium tuberculosis complex. Proceedings of the National Academy of Sciences 99(6): 3684-3689.

Cantas L. \& Suer K. (2014). The important bacterial zoonoses in "one health" concept. Frontiers in Public Health 2: 1-8.
DOI: https://doi.org/10.3389/fpubh.2014.00144

Cardoso M.A., Cardoso R.F., Hirata R.D.C., Hirata M.H., Leite C.Q.F., Santos A.C.B., Siqueira V.L.D., Okano W., Rocha N. \& Lonardoni M.V.C. (2009). Direct detection of Mycobacterium bovis in bovine lymph nodes by PCR. Zoonoses and Public Health 56(8): 465-470.

Chatterjee M., Bhattacharya S., Karak K. \& Dastidar S.G. (2013). Effects of different methods of decontamination for successful cultivation of Mycobacterium tuberculosis. The Indian Journal of Medical Research 138(4): 541-548.

Cheeseman C.L., Wilesmith J.W. \& Stuart F.A. (1989). Tuberculosis: the disease and its epidemiology in the badger, a review. Epidemiology and Infection 103(1): 113-125.

DOI: https://doi.org/10.1017/s0950268800030417

Collins J.D. (2006). Tuberculosis in cattle: strategic planning for the future. Veterinary Microbiology 112(2-4): 369-381. DOI: https://doi.org/10.1016/j.vetmic.2005.11.041

Corner L. (1994). Post mortem diagnosis of Mycobacterium bovis infection in cattle. Veterinary Microbiology 40(1-2): 53-63. DOI: https://doi.org/10.1016/0378-1135(94)90046-9

Cosivi O., Grange J.M., Daborn C.J., Raviglione M.C., Fujikura T., Cousins D., Robinson R.A., Huchzermeyer H.F., de Kantor I. \& Meslin F.X. (1998). Zoonotic tuberculosis due to Mycobacterium bovis in developing countries. Emerging Infectious Diseases 4(1): 59-70.

DOI: https://doi.org/10.3201/eid0401.980108

De La Rua-Domenech R. (2006). Human Mycobacterium bovis infection in the United Kingdom: incidence, risks, control measures and review of the zoonotic aspects of bovine tuberculosis. Tuberculosis 86(2): 77-109. DOI: https://doi.org/10.1016/j.tube.2005.05.002

De La Rua-Domenech R., Goodchild A.T., Vordermeier H.M., Hewinson R.G., Christiansen K.H \& Clifton-Hadley R.S. (2006). Ante mortem diagnosis of tuberculosis in cattle: a review of the tuberculin tests, $\gamma$-interferon assay and other ancillary diagnostic techniques. Research in Veterinary Science 81(2): 190-210.

DOI: https://doi.org/10.1016/j.rvsc.2005.11.005

Department of Animal Production and Health (DAPH) (2016). Annual Report. Department of Animal Production and Health, Peradeniya, Sri Lanka.

Department of Census and Statistics (2019). Slaughter Statistics. Agriculture and Environment Statistics Division, Department of Census and Statistics, Sri Lanka.

Echeverría G., Ron L., León A.M., Espinosa W., BenítezOrtiz W. \& Proaño-Pérez F. (2014). Prevalence of bovine tuberculosis in slaughtered cattle identified by nested-PCR in abattoirs from two dairy areas of Ecuador. Tropical Animal Health and Production 46(6): 1015-1022 DOI: https://doi.org/10.1007/s11250-014-0610-9

Ereqat S., Nasereddin A., Levine H., Azmi K., Al-Jawabreh A., Greenblatt C. L., Abdeen Z. \& Bar-Gal G.K. (2013). Firsttime detection of Mycobacterium bovis in livestock tissues and milk in the West Bank, Palestinian Territories. PLoS Neglected Tropical Diseases 7(9): e2417. DOI: https://doi.org/10.1371/journal.pntd.0002417 
FAO (2019). Protecting people and animals from disease threats. Food and Agriculture Organization of the United Nations, Quebec City, Canada.

Fine A.E., Bolin, C.A., Gardiner, J.C. \& Kaneene, J.B. (2011). A study of the persistence of Mycobacterium bovis in the environment under natural weather conditions in Michigan, USA. Veterinary Medicine International 2011: 1-12. DOI: https://doi.org/10.4061/2011/765430

Fitzgerald S.D. \& Kaneene J.B. (2013). Wildlife reservoirs of bovine tuberculosis worldwide: hosts, pathology, surveillance, and control. Veterinary Pathology 50(3): 488-499.

DOI: https://doi.org/10.1177 \%2F0300985812467472

Gizaw T.T., Minalu B.A. \& Asfaw Y.T. (2017). Prevalence of bovine tuberculosis using abattoir meat inspection in cattle slaughtered at Gondar Elfora abattoir, North Ethiopia. Animal and Veterinary Sciences 5(5): 89-96. DOI: https://doi.org/ https://doi.org/10.11648/j. avs. 20170505.15

Good M. \& Duignan A. (2011). Perspectives on the history of bovine $\mathrm{TB}$ and the role of tuberculin in bovine TB eradication. Veterinary Medicine International 2011:1-11. DOI: https://doi.org/10.4061/2011/410470

Haddad N., Masselot M. \& Durand B. (2004). Molecular differentiation of Mycobacterium bovis isolates. Review of main techniques and applications. Research in Veterinary Science 76(1): 1-18. DOI: https://doi.org/10.1016/s0034-5288(03)00078-x

Jayasumana M.T.L.K., Galappaththi T.I., Pushpakumara P.G.A., Gamage C.D., Smith N.H. \& Jinadasa H. R. N. (2018a). Screening milk for bovine tuberculosis in dairy farms in Central Province, Sri Lanka. Tropical Agricultural Research 30(1): 12-18.

DOI: https://doi.org/10.4038/tar.v30i1.8274

Jayasumana M.T.L.K., Kumara Y.H.P.S.N., Amarasinghe A.A.A.W.K., Pushpakumara P.G.A., De Silva L.N.A., Alexander P.A.B.D., Gunawardena G.S.P.de S., Smith N.H., Magana-Arachchi D. \& Jinadasa H.R.N. (2018b). Molecular characterization of Mycobacterium bovis isolates from Central province and North Western province of Sri Lanka using MIRU-VNTR typing. Proceedings of the Annual Sessions of Sri Lanka Veterinary Association, Kandy, Sri Lanka.

Kent P.T. (1985). Public Health Mycobacteriology: a Guide for the Level III Laboratory. Department of Health and Human Services, USA.

Kinde H., Mikolon A., Rodriguez-Lainz A., Adams C., Walker R.L., Cernek-Hoskins S., Treviso S., Ginsberg M., Rast R. \& Harris B. (2007). Recovery of Salmonella, Listeria monocytogenes and Mycobacterium bovis from cheese entering the United States through a noncommercial land port of entry. Journal of Food Protection 70(1): 47-52. DOI: https://doi.org/10.4315/0362-028x-70.1.47

Kumara U.G.V.S.S., Salgadu M.A., Kumara V., Gunawardena G.S.P.D.S., Smith N.H. \& Jinadasa H.R.N. (2015). Isolation and molecular identification of Mycobacterium bovis from lung lesions in a cattle carcass at a slaughter house in Sri Lanka. Sri Lanka Veterinary Journal 62:11-14.
Kumara Y.H.P.S.N., Salgadu M.A., Weerasekara D.K., Nishanantha K., Weerasekara D.K., Magana-Arachchi D.N., Pushpakumara P.G.A., De Silva. L.N.A., Alexender P.A.B.D., Jinadasa H.R.N. \& Amarasinghe A.A.W.K. (2014). Detection of bovine tuberculosis in Sri Lanka using molecular techniques. Proceedings of One Health International Conference, Kandy, Sri Lanka.

Kumara Y.H.P.S.N. (2017). Prevalence and associated risk factors of bovine tuberculosis in cattle and buffaloes in the Central province of Sri Lanka. M. Phil thesis, University of Peradeniya, Peradeniya, Sri Lanka

Leite C.Q.F., Anno I.S., Leite S.R., Roxo E., Morlock G.P. \& Cooksey R.C. (2003). Isolation and identification of mycobacteria from livestock specimens and milk obtained in Brazil. Memórias do Instituto Oswaldo Cruz 98(3): 319-323.

DOI: https://doi.org/10.1590/s0074-02762003000300005

Lobue P., Betacourt W., Peter C. \& Moser K. (2003). Epidemiology of Mycobacterium bovis disease in San Diego County, 1994-2000. The International Journal of Tuberculosis and Lung Disease 7(2): 180-185.

Max V., Paredes L., Rivera A. \& Ternicier C. (2011). National control and eradication program of bovine tuberculosis in Chile. Veterinary Microbiology 151(1-2): 188-191.

DOI: https://doi.org/10.1016/j.vetmic.2011.02.043

Menin Á., Fleith R., Reck C., Marlow M., Fernandes P., Pilati C. \& Báfica A. (2013). Asymptomatic cattle naturally infected with Mycobacterium bovis present exacerbated tissue pathology and bacterial dissemination. PloS ONE 8(1): e53884

DOI: https://doi.org/10.1371/journal.pone.0053884

Michel A.L., Müller B. \& Van Helden P.D. (2010). Mycobacterium bovis at the animal-human interface: A problem, or not? Veterinary Microbiology 140(3-4): 371381.

Miller R.S. \& Sweeney S.J. (2013). Mycobacterium bovis (bovine tuberculosis) infection in North American wildlife: current status and opportunities for mitigation of risks of further infection in wildlife populations. Epidemiology \& Infection 141(7): 1357-1370. DOI: https://doi.org/10.1017/S0950268813000976

Müller B., Dürr S., Alonso S., Hattendorf J., Laisse C.J., Parsons S.D., Van Helden P.D. \& Zinsstag J. (2013). Zoonotic Mycobacterium bovis-induced tuberculosis in humans. Emerging Infectious Diseases, 19(6): 899-908.

Müller B., Steiner B., Bonfoh B., Fané A., Smith N.H. \& Zinsstag J. (2008). Molecular characterisation of Mycobacterium bovis isolated from cattle slaughtered at the Bamako abattoir in Mali. BMC Veterinary Research 4(1): $1-6$.

DOI: https://doi.org/10.1186/1746-6148-4-26

National Programme for Tuberculosis Control and Chest Diseases (NPTCCD) (2016). National Manual for Tuberculosis Control, Health Information Management Unit, National Programme for Tuberculosis Control and Chest Diseases (NPTCCD). Sri Lanka.

O’brien D.J., Schmitt S.M., Fitzgerald S.D., Berry D.E. \& Hickling G.J. (2006). Managing the wildlife reservoir of 
Mycobacterium bovis: the Michigan, USA, experience. Veterinary Microbiology 112(2-4): 313-323.

DOI: https://doi.org/10.1016/j.vetmic.2005.11.014

OIE (2008). Manual of Diagnostic Tests and Vaccines for Terrestrial Animals. Organization of International Epizootics, Paris, France.

Palomino J.C. \& Portaels F. (1998). Effects of decontamination methods and culture conditions on viability of Mycobacterium ulcerans in the BACTEC System. Journal of Clinical Microbiology 36: 402-408.

Perera B.V.P., Salgadu M.A., Gunawardena G.S.P.S., Smith N.H. \& Jinadasa H.R.N. (2014). First confirmed case of fatal tuberculosis in a wild Sri Lankan elephant. Gajah 41: 28-31.

Proaño-Pérez F., Benitez-Ortiz W., Desmecht D., Coral M., Ortiz J., Ron L., Portaels F., Rigouts L. \& Linden A. (2011). Post-mortem examination and laboratory-based analysis for the diagnosis of bovine tuberculosis among dairy cattle in Ecuador. Preventive Veterinary Medicine 101(1-2): 65-72. DOI: https://doi.org/10.1016/j.prevetmed.2011.04.018

Quinn P.J., Markey B.K., Leonard F.C., Fitzpatrick E., Fanning S. \& Hartigan P. (2015). Veterinary Microbiology and Microbial Disease. John Wiley \& Sons, New Jersey, USA.

Radunz B. (2006). Surveillance and risk management during the latter stages of eradication: experiences from Australia. Veterinary Microbiology 112(2-4): 283-290. DOI: https://doi.org/10.1016/j.vetmic.2005.11.017

Sa'idu A.S., Okolocha E.C., Dzikwi A.A., Gamawa A.A., Ibrahim S., Kwaga J.K.P., Usman A. \& Maigari S.A. (2015a). Public health implications and risk factors assessment of Mycobacterium bovis infections among abattoir personnel in Bauchi state, Nigeria. Journal of Veterinary Medicine 2015: 1-5.

Sa'idu A.S., Okolocha E.C., Dzikwi A.A., Kwaga J.K.P., Gamawa A.A., Usman A., Maigari S.A. \& Ibrahim S. (2015b). Detection of Mycobacterium bovis in organs of slaughtered cattle by DNA-based polymerase chain reaction and Ziehl-Neelsen techniques in Bauchi State, Nigeria. Journal of Veterinary Medicine 2015: 1-7. DOI: https://doi.org/10.1155/2015/921868

Schiller I., Oesch B., Vordermeier H.M., Palmer M.V., Harris B.N., Orloski K.A., Buddle B.M., Thacker T.C., Lyashchenko K.P. \& Waters W.R. (2010). Bovine tuberculosis: a review of current and emerging diagnostic techniques in view of their relevance for disease control and eradication. Transboundary and Emerging Diseases 57(4): 205-220.

DOI: https://doi.org/10.1111/j.1865-1682.2010.01148.x

Silva D.A.V.D., Siconelli M.J.L., Bürger K.P. \& Keid L.B. (2018a). Comparison between tests for tuberculosis diagnosis in slaughtered bovines. Arquivos do Instituto Biológico 85: 1-8.

Silva S.C.G., Alves A.D.D.F., De Oliveira A.T.J., De Sá P.C.L., De Souza F.A.F., Cárdenas N.C., Neto J.S.F., Heinemann M.B., De Azevedo S.S. \& De Medeiros T.M.B.A. (2018b). Isolation and identification of Mycobacterium bovis in cattle slaughtered from an abattoir in Garanhuns. Semina: Ciências Agrárias, Londrina 39(1): 157-166.
DOI: https://doi.org/10.5433/1679-0359.2018v39n1p157

Smith N.H., Gordon S.V., De La Rua-Domenech R., CliftonHadley R.S. \& Hewinson R.G. (2006). Bottlenecks and broomsticks: the molecular evolution of Mycobacterium bovis. Nature Reviews Microbiology 4(9): 670-681.

DOI: https://doi.org/10.1038/nrmicro1472

Souza R.F.P.D., Luvizotto M.C.R., Fernandes J.O.M. \& Ferrari H. F. (2013). Caracterização histomorfológica de lesões granulomatosas sugestivas de tuberculose ganglionar e pulmonar em bovinos abatidos na região noroeste do estado de SãoPaulo. Ciências Agrárias e da Saúde 9: 27-35.

Srinivasan S., Easterling L., Rimal B., Niu X.M., Conlan A.J., Dudas P. \& Kapur V. (2018). Prevalence of Bovine Tuberculosis in India: A systematic review and metaanalysis. Transboundary and Emerging Diseases 65(6): 1627-1640.

Sunder S., Lanotte P., Godreuil S., Martin C., Boschiroli M.L. \& Besnier J.M. (2009). Human-to-human transmission of tuberculosis caused by Mycobacterium bovis in immunocompetent patients. Journal of Clinical Microbiology 47(4): 1249-1251

DOI: https://doi.org/10.1128/jcm.02042-08

Swift B.M., Convery T.W. \& Rees C.E. (2016). Evidence of Mycobacterium tuberculosis complex bacteraemia in intradermal skin test positive cattle detected using phageRPA. Virulence 7(7): 779-788

DOI: https://doi.org/10.1080/21505594.2016.1191729

Thoen C.O., Lobue P. \& De Kantor I. (2006). The importance of Mycobacterium bovis as a zoonosis. Veterinary Microbiology, 112(2-4): 339-345.

Thrusfield M. (2005). Veterinary Epidemiology. Blackwell Science Ltd., Cambridge, USA.

Tibebu M., Mekonnen W., Awoke T., Gebre-Selassie S. \& Yamuah L. (2014). A high prevalence of tuberculosis among dairy farm workers in Addis Ababa and its surroundings. Journal of Mycobacterium Disease 4(139): 2161-1068. DOI: https://doi.org/10.4172/2161-1068.1000139

Tripathi K., Tripathi P.C., Nema S., Shrivastava A.K., Dwiwedi K. \& Dhanvijay A.K. (2014). Modified Petroff's method: an excellent simplified decontamination technique in comparison with Petroff's method. International Journal of Recent Trends in Science and Technology 10(3): 461-464.

Une Y. \& Mori T. (2007). Tuberculosis as a zoonosis from a veterinary perspective. Comparative Immunology, Microbiology and Infectious Diseases 30(5-6): 415-425. DOI: https://doi.org/10.1016/j.cimid.2007.05.002

Varello K., Pezzolato M., Mascarino D., Ingravalle F., Caramelli M. \& Bozzetta E. (2008). Comparison of histologic techniques for the diagnosis of bovine tuberculosis in the framework of eradication programs. Journal of Veterinary Diagnostic Investigation 20(2): 164-169.

DOI: https://doi.org/10.1177/104063870802000204

Wagari A. (2016). Review on diagnostic techniques of bovine tuberculosis. International Journal of Biochemistry, Biophysics and Molecular Biology 1(1): 11-17. DOI: https://doi.org/ 10.11648/j.ijbbmb.20160101.12

Warren R., Gey V.P.N., Barnard M., Hesseling A., Engelke E., De Kock M., Gutierrez M., Chege G., Victor T. \& Hoal 
E. (2006). Differentiation of Mycobacterium tuberculosis complex by PCR amplification of genomic regions of difference. The International Journal of Tuberculosis and Lung Disease 10(7): 818-822.

Westrell T., Ciampa N., Boelaert F., Helwigh B., Korsgaard H., Chriél M., Ammon A. \& Mäkelä P. (2009). Zoonotic infections in Europe in 2007: a summary of the EFSAECDC annual report. Eurosurveillance, 14(3): 1-3.

World Health Organization (WHO) (2017). Roadmap for zoonotic tuberculosis. World Health Organization, Geneva,
Switzerland.

Wobeser G. (2009). Bovine tuberculosis in Canadian wildlife: an updated history. The Canadian Veterinary Journal 50(11): 1169-1176.

Yahyaoui-Azami H., Aboukhassib H., Bouslikhane M., Berrada J., Rami S., Reinhard M., Gagneux S., Feldmann J., Borrell S. \& Zinsstag J. (2017). Molecular characterization of bovine tuberculosis strains in two slaughterhouses in Morocco. BMC Veterinary Rresearch 13(1): 272-279. DOI: https://doi.org/10.1186/s12917-017-1165-6 